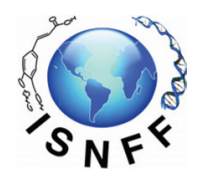

\title{
Comprehensive study of the lipid from whelk (Chlorostoma rusticum and Neverita didyma) with emphasis on characterization of phospholipid molecular species by shot-gun strategy
}

\author{
Zhong-Yuan Liu ${ }^{\mathrm{a} \#}$, Kai-Qi Gang ${ }^{\mathrm{a} \#}$, Fa-Wen Yin ${ }^{\mathrm{a}, \mathrm{b}}$, Hong-Kai Xie ${ }^{\mathrm{c}}$, \\ Liang Song ${ }^{\mathrm{a}, \mathrm{b}}$ and Da-Yong Zhou ${ }^{\mathrm{a}, \mathrm{b}^{*}}$
}

\begin{abstract}
aSchool of Food Science and Technology, Dalian Polytechnic University, Dalian, PR China, 116034
${ }^{b}$ National Engineering Research Center of Seafood, Dalian, PR China, 116034

${ }^{\mathrm{c} B e i j i n g}$ Advanced Innovation Centre of Food Nutrition and Human Health, China Agricultural University, Beijing, China, 100083

\#The authors contributed equally to this work.

*Corresponding author: Da-Yong Zhou, School of Food Science and Technology, Dalian Polytechnic University, Dalian, PR China, 116034. E-mail: zdyzf1@163.com

DOI: $10.31665 /$ JFB.2019.8210

Received: December 20, 2019; Revised received \& accepted: December 30, 2019

Citation: Liu, Z.-Y., Gang, K.-Q., Yin, F.-W., Xie, H.-K., Song, L., and Zhou, D.-Y. (2019). Comprehensive study of the lipid from whelk (Chlorostoma rusticum and Neverita didyma) with emphasis on characterization of phospholipid molecular species by shot-gun strategy. J. Food Bioact. 8: 84-91.
\end{abstract}

\begin{abstract}
In the present study, an effective shot-gun lipidomic methodology was established to determine the glycerophospholipid (GP) molecular species of two species of edible marine whelks (Chlorostoma rusticum and Neverita didy$\mathrm{ma}$ ). Simultaneously, the lipid content, lipid classes, phospholipid (PL) subclasses and fatty acid compositions were also investigated. Over 210 molecular species of GP including glycerophosphocholine, lysoglycerophosphocholine, glycerophosphoethanolamine, lysoglycerophosphoethanolamine, glycerophosphoserine, lysoglycerophosphoserine, glycerophosphoinositol and lysoglycerophosphoinositol were characterized in the two abovementioned whelk species. The predominant GP molecular species contained n-3 long chain polyunsaturated fatty acid (n-3 LC-PUFA), especially docosahexaenoic acid and eicosapentaenoic acid. Meanwhile, PL (57.70-58.86\% of total lipids) and PUFA (21.69-37.68\% of total FA) take large proportions in whelk lipids. Among PL, phosphatidylcholine (50.58-52.41 mol\%) and phosphatidylethanolamine (27.67-32.73 mol\%) were dominant. Therefore, marine whelks turn out to be promising source of $n-3$ LC-PUFA existed in PL form and thus directly contribute to the health benefits of consumer.
\end{abstract}

Keywords: Marine whelk; Lipid class composition; Phospholipid class composition; Phospholipid molecular species; n-3 LC-PUFA.

1. Introduction

Lipid is the main energy supply material for human body, which can provide more than twice the energy of sugar and protein in the metabolism (Barden and Decker, 2016). In addition, some fatty acids (FAs) are crucial for human body to remain healthy, especially n-3 long chain polyunsaturated fatty acids (n-3 LC-PUFAs) represented by docosahexaenoic acid (DHA) and eicosapentae- noic acid (EPA), which play significant roles in various aspects toward human health such as cardiovascular protection, anti-inflammation, anti-hypertension, anti-allergies, brain development as well as renal function (Riediger et al., 2009). Therefore, it was recommended by many countries that a daily consumption of 250-1,000 mg of EPA/DHA provides health benefits (Kuratko and Salem, 2013).

Phospholipids (PLs), the major part of polar lipids in seafoods, have been reported to possess versatile biological function such as 
reducing cholesterol absorption, decreasing the risk of cardiovascular diseases, enhancing liver functions as well as brain function development (Ali et al., 2019; Arranz and Corredig, 2017). The current interest of PLs mainly comes from their effectiveness to incorporate n-3 LC-PUFAs to the cell membrane, as they exhibit better absorption and utilization than triglycerides (TAGs) (Cilla et al., 2016). Eggs, soybeans and fishes are main source of dietary PLs now, among which fishes are attracting more and more attention due to the abundant n-3 LC-PUFAs in PLs. In recent years, incremental studies have reported that marine shellfishes also are a rich source of PLs that contain n-3 LC-PUFAs. However, most of the published studies on characterization of PL molecular species of marine shellfish mainly concentrate on bivalve shellfish including oysters, clams, scallops, etc. (Boselli et al., 2012; Chen et al, 2012; Liu et al. 2017), but only few on univalve shellfish. To provide reliable nutritional and functional information and support for the better utilization of univalve shellfish, comprehensive characterization of lipid profiles in univalve shellfish is required.

Whelks are excellent candidate univalve shellfish for aquaculture and functional foods (Tang et al., 2016), among which Chlorostoma rusticum and Neverita didyma are the main edible species. An efficient shotgun lipidomic strategy was established in the present work to characterize the molecular species of glycerophospholipid (GP) including glycerophosphocholine (GPCho), lysoglycerophosphocholine (LGPCho), glycerophosphoethanolamine (GPEtn), lysoglycerophosphoethanolamine (LGPEtn), lycerophosphoserine (GPSer), lysoglycerophosphoserine (LGPSer), glycerophosphoinositol (GPIns), and lysoglycerophosphoinositol (LGPIns) in the two abovementioned species of whelks. Meanwhile, the lipid content and quality of lipid classes, PL subclasses and FA compositions were also investigated. This work will reveal the specific health benefits of lipids in whelks in detail as well as provide theoretical basis for utilization of whelk as a novel source of functional food.

\section{Materials and methods}

\subsection{Materials}

Two species of marine edible whelks (Chlorostoma rusticum and Neverita didyma) that harvested in July were selected and purchased from a local market in Dalian, Liaoning, China. After husking by hand, about $800 \mathrm{~g}$ of meat were lyophilized with a 2KBTES-55 freeze-dryer (VirTis Co., Gardiner, NY, USA) for $70 \mathrm{~h}$, crushed into a fine powder and stored at $-30{ }^{\circ} \mathrm{C}$ for further use. GP standards of GPCho 12:0/12:0, GPEtn 12:0/12:0, GPSer 12:0/12:0 and GPIns 8:0/8:0 were purchased from Avanti Polar Lipids, INC (Alabaster, AL, USA). Deuterated chloroform $\left(\mathrm{CDCl}_{3}\right)$, methanol (MeOD), triethyl phosphate (TEP), cesium carbonate $\left(\mathrm{CsCO}_{3}\right)$ and deuterated water $\left(\mathrm{D}_{2} \mathrm{O}\right)$ were purchased from Aladdin Reagent Co., Ltd. (Shanghai, China). Other reagents were of analytical grade from Damao Chemical Reagent Co., Ltd. (Tianjin, China).

\subsection{Lipid extraction}

Total lipid from the two species of whelks Chlorostoma rusticum and Neverita didyma was extracted according to the widely adopted methyl tert-butyl ether (MTBE) method (Matyash et al., 2008), with little modification. Briefly, $10 \mathrm{~g}$ whelk powder sample was put in a $50 \mathrm{~mL}$ polytetrafluoroethylene tubes, and then an organic reagent mixture of methanol $(15 \mathrm{~mL})$ and MTBE $(50 \mathrm{~mL})$ was added to each sample. After stirring the mixture at $30{ }^{\circ} \mathrm{C}$ for 1 $\mathrm{h}, 12.5 \mathrm{~mL}$ of deionized water was added to the polytetrafluoroethylene tubes. Shaking the tubes for complete mixing, then the system was centrifuged at $7,800 \mathrm{~g}$ for $10 \mathrm{~min}$. After collecting and transferring all the organic phase to a new glass, and then the rest was re-extracted following the same procedure. The organic phase was collected and evaporated under a tender nitrogen flow at 35 ${ }^{\circ} \mathrm{C}$. The lipids from the two whelk materials were stored at $-80{ }^{\circ} \mathrm{C}$ for less than 2 weeks for further analysis.

\subsection{Determination of lipid class composition}

An Iatroscan MK-6S thin layer chromatography-flame ionization detection (TLC-FID) Analyzer (Iatron Inc., Tokyo, Japan) was used to determine the lipid class composition according to Yin et al. (2015).

\subsection{Determination of fatty acid composition}

FA compositions were first derived with methanol to form FA methyl ester then determined with an Agilent 7890B GC-5977C MSD (Agilent, Palo Alto, CA, USA) equipped with HP-5-MS capillary column $(30 \mathrm{~m} \times 0.25 \mathrm{~mm}, 0.25 \mu \mathrm{m})$ (Agilent) according to the procedure previously described (Yin et al., 2015).

\subsection{PL classes quantification by ${ }^{31} P$ NMR}

The determination of PL classes was conducted with an Avance III $400 \mathrm{MHz}$ NMR spectrometer (Bruker, Karlsruhe, Germany) according to one previous study (Gang et al., 2018).

\subsection{Mass spectrometric analysis of whelk lipids}

In this study, qualitative and quantitative of PL molecular species were achieved by using a hybrid API 4000 Qtrap (AB Sciex, Foster City, CA, USA) quadrupole-linear ion trap (QqLIT) mass spectrometer (MS) with a Turbo V electrospray ionization (ESI) source interface, and a computer platform equipped with HPLCMS/MS Solution Analyst software 1.6.1 (AB Sciex, Foster City, CA, USA). Whelk lipids were dissolved in a mixture of chloroform and methanol $(2: 1, \mathrm{v} / \mathrm{v})$, which contained $0.1 \%$ of formic acid to improve the ionization efficiency, and directly introduced into the ESI source though a syringe pump after filtering by a $0.22 \mu \mathrm{m}$ organic membrane. The whelk lipid concentration was $50 \mu \mathrm{g} / \mathrm{mL}$, and the flow rate for analysis of GPCho/LGPCho, GPEtn/LGPEtn, GPSer/LGPSer and GPIns/LGPIns was 2, 10, 10 and $20 \mu \mathrm{L} / \mathrm{min}$, respectively. In characteristic scan mode, precursor-ion scanning (PIS) and neutral loss scanning (NLS) was operated in the positive ion mode for PL identification, while the enhanced product ion (EPI) scanning that conducted in the negative ion mode for FA explication. The instrument parameters were identical with our previous study (Liu et al., 2017).

The semi-quantitation of the same GP molecular species between lipids recovered from different whelk species was achieved by using an internal standard as previously described (Liu et al., 2017; Yin et al., 2016). In this study, four GP standards including GPCho 12:0/12:0 (inner standard for GPCho/LGPCho), GPEtn 12:0/12:0 (inner standard for GPEtn/LGPEtn), GPSer 12:0/12:0 
Table 1. Class compositions (\%) of the lipids recovered from two species of whelks

\begin{tabular}{lllllll}
\hline Species & PL & TAG & DAG & MAG & FFA & CHO \\
\hline Chlorostoma rusticum & $52.70 \pm 0.18^{\mathrm{b}}$ & $31.91 \pm 0.18$ & $0.41 \pm 0.02^{\mathrm{b}}$ & $0.57 \pm 0.04^{\mathrm{b}}$ & $3.71 \pm 0.07^{\mathrm{a}}$ & $10.60 \pm 0.08^{\mathrm{a}}$ \\
Neverita didyma & $58.86 \pm 0.39^{\mathrm{a}}$ & $32.01 \pm 0.47$ & $0.53 \pm 0.01^{\mathrm{a}}$ & $0.96 \pm 0.09^{\mathrm{a}}$ & $1.11 \pm 0.08^{\mathrm{b}}$ & $6.66 \pm 0.49^{\mathrm{b}}$ \\
\hline
\end{tabular}

a,bValues in the same column with different lower-case letters are significantly different at $P<0.05$. Abbreviations: PL, phospholipid; TAG, triacylglycerol; DAG, diacylglycerol; MAG, monoacylglycerol; FFA, free fatty acid; $\mathrm{CHO}$, cholesterol.

(inner standard for GPSer/LGPSer) and GPIns 8:0/8:0 (inner standard for GPIns/LGPIns) were added to the samples with concentration of $1.00,1.50,0.15$, and $0.15 \mu \mathrm{g} / \mathrm{mL}$, respectively, before injection for MS analysis.

\subsection{Statistical analysis}

The experiments were conducted in triplicate. Data were presented as mean \pm standard deviation (SD). The experimental data for statistical analysis was achieved by using SPSS 16.0 software (SPSS Inc., Chicago, IL, USA). Independent-samples $T$ text was adopted to compare the differences between means. $P$ values $<0.05$ were considered significant.

\section{Results and discussion}

\subsection{Lipid content}

The dried meat of Chlorostoma rusticum and Neverita didyma contained 13.67 and $7.12 \%$ lipids, respectively. Previous studies showed that the lipid contents of whelks Mytilus galloprovincial, Neptunea lyrata and Bulimulus dealbatus were 9.6, 10.8 and 7.3\% (dry basis) (Miletic et al., 1991; Beach et al., 2009; Zarai et al., 2011), respectively, which indicate that the lipid contents varied in different species of whelks.

\subsection{Lipid class compositions}

As shown in Table 1, total lipids that extracted from the two species of whelks had similar lipid profiles. They were both consisted of PL, TAG, diacylglycerols (DAG), monoacylglycerols (MAG), free fatty acids (FFA) and cholesterols (CHO), among which PL (52.70-58.86\% of total lipids) and TAG (31.91-32.01\% of total lipids) constituted the major part of the lipids. Similarly, previous studies have also reported that PL was dominant in whelk lipids. For example, similar observations indicated PL accounted for 56.3 and $59.8 \%$ of total lipids, respectively, in whelks Turbo cornutus (Saito and Aono, 2014) and Haustrum scobina (Carrasco et al., 2016).

PLs, especially GPs, act as the principal structural constituents of cell or biological membranes. In the perception of lipid nutrition, it has been commonly accepted that PL are highly effective in delivering their FA residues for incorporation into the membranes and altered the FA composition of membrane PLs within specific cell type. Consequently, cellular functions including signaling and transport, as well as the membrane bound enzymes activity could be modulated or greatly affected by dietary PLs (Küllenberg et al., 2012). Therefore, dietary consumption of PLs contributes to a series of health benefits such as reducing the risk of cardiovascular disease, reducing blood cholesterol levels, reducing inflammatory reactions, enhancing the body's immunity, preventing hepatic disorders, and improving brain function (Küllenberg et al., 2012; Restuccia et al., 2012). The current study implied that Chlorostoma rusticum and Neverita didyma contained a large amount of PL, which indicate their potential health benefits.

\subsection{Phospholipid class composition}

As demonstrated in Table 2, phosphocholine (PC), phosphoethanolamine (PE), phosphatidylinositol (PI), phosphatidylserine (PS), phosphatidic acid (PA), phosphatidylglycerol (PG) and lysophosphatidylcholine (LPC) were observed in the whelk lipids. Obviously, PC (50.58-52.41 mol\%) and PE (27.67-32.73 mol\%) were dominant. In contrast to PC and PE, LPC (3.20-8.86 mol\%) and PG (3.76-11.05 mol\%) just take a small proportion. However, PI (2.10 mol\%), PS (4.81 mol\%) and PA (2.81 mol\%) were only detected in the lipid of Neverita didyma. Consist with this work, previous similar study also indicated that PC (62.81\%) and PE $(11.70 \%)$ were dominant PL classes of lipid in sea snail Chromodoris tinctoria (Zhukova, 2014).

Different types of PLs vary in their headgroup, and therefore have different health effects. For example, PC, also known as lecithin, is the most abundant PL of all mammalian cell types and subcellular organelles, and is essential for brain land liver function, lipid metabolism and transport, cell membranes signaling, cell composition and repair (Asomaning et al., 2017); PE, which is the second most abundant PL in mammalian membranes, is also essential for membrane integrity and cell division (Calzada et al, 2016); PS, though a quantitatively minor membrane PL part, it is widely distributed throughout organelle membranes except endoplasmic reticulum, and it is required for human brain biochemistry, physiology, and function (Glade and Smith, 2015); PA, the simplest GP present in cells, is now a widely accepted second messenger for its important role in cellular signaling and membrane dynamics in all eukaryotes (Kooijman and Burger, 2009). With the diverse PL classes exist in the lipids in of Chlorostoma rusticum and Neverita

Table 2. Phospholipid class compositions (mol\%) of the lipids recovered from two species of whelks

\begin{tabular}{llllllll}
\hline Species & PC & PE & LPC & PI & PS & PG & PA \\
\hline Chlorostoma rusticum & $52.41 \pm 0.42^{\mathrm{a}}$ & $27.67 \pm 0.01^{\mathrm{b}}$ & $8.86 \pm 0.00^{\mathrm{a}}$ & nd & nd & $11.05 \pm 0.02^{\mathrm{a}}$ & nd \\
Neverita didyma & $50.58 \pm 0.23^{\mathrm{b}}$ & $32.73 \pm 0.31^{\mathrm{a}}$ & $3.20 \pm 0.00^{\mathrm{b}}$ & $2.10 \pm 0.01$ & $4.81 \pm 0.01$ & $3.76 \pm 0.01^{\mathrm{b}}$ & $2.81 \pm 0.01$ \\
\hline
\end{tabular}

a,b Values in the same column with different lower-case letters are significantly different at $P<0.05$. Abbreviations: PC, phosphatidylcholine; PE, phosphatidylethanolamine; LPC, lysophosphatidylcholine; PI, phosphatidylinositol; PS, phosphatidylserine; PG, phosphatidylglycerol; PA, phosphatidic acid. 
Table 3. Fatty acid compositions (\%) of the lipids recovered from two species of whelks

\begin{tabular}{lll}
\hline Fatty acid & Chlorostoma rusticum & Neverita didyma \\
\hline C14:0 & $4.04 \pm 0.09^{\mathrm{a}}$ & $2.39 \pm 0.04^{\mathrm{b}}$ \\
C15:0 & $1.42 \pm 0.13^{\mathrm{a}}$ & $0.65 \pm 0.11^{\mathrm{b}}$ \\
C16:1n-7 & $6.28 \pm 0.25^{\mathrm{a}}$ & $5.38 \pm 0.30^{\mathrm{b}}$ \\
C16:0 & $23.36 \pm 0.41^{\mathrm{a}}$ & $16.14 \pm 0.33^{\mathrm{b}}$ \\
C17:1n-7 & $0.51 \pm 0.06$ & $\mathrm{nd}$ \\
C17:0 & $3.12 \pm 0.48^{\mathrm{a}}$ & $1.86 \pm 0.07^{\mathrm{b}}$ \\
C18:4n-3 & $0.46 \pm 0.04$ & $\mathrm{nd}$ \\
C18:2n-6 & $3.34 \pm 0.25^{\mathrm{a}}$ & $1.65 \pm 0.23^{\mathrm{b}}$ \\
C18:1n-9 & $26.58 \pm 0.56^{\mathrm{a}}$ & $7.38 \pm 0.33^{\mathrm{b}}$ \\
C18:0 & $3.77 \pm 0.32^{\mathrm{b}}$ & $10.68 \pm 0.97^{\mathrm{a}}$ \\
C20:4n-6 & $4.08 \pm 0.20^{\mathrm{a}}$ & $2.47 \pm 0.45^{\mathrm{b}}$ \\
C20:5n-3 & $3.17 \pm 0.06^{\mathrm{b}}$ & $11.00 \pm 0.73^{\mathrm{a}}$ \\
C20:2n-9 & $1.66 \pm 0.19^{\mathrm{a}}$ & $0.89 \pm 0.12^{\mathrm{b}}$ \\
C20:1n-9 & $9.73 \pm 0.64^{\mathrm{b}}$ & $12.78 \pm 0.49^{\mathrm{a}}$ \\
C20:1n-7 & nd & $4.94 \pm 0.26$ \\
C22:6n-3 & $0.40 \pm 0.03^{\mathrm{b}}$ & $11.10 \pm 0.08^{\mathrm{a}}$ \\
C22:4n-6 & $0.61 \pm 0.09^{\mathrm{b}}$ & $1.12 \pm 0.13^{\mathrm{a}}$ \\
C22:5n-3 & $1.77 \pm 0.27^{\mathrm{b}}$ & $2.67 \pm 0.35^{\mathrm{a}}$ \\
C22:2n-9 & $4.60 \pm 0.45^{\mathrm{b}}$ & $6.78 \pm 0.44^{\mathrm{a}}$ \\
C22:2n-6 & $1.61 \pm 0.21$ & $\mathrm{nd}$ \\
SFA & $35.21 \pm 0.16^{\mathrm{a}}$ & $32.06 \pm 0.22^{\mathrm{b}}$ \\
MUFA & $43.10 \pm 0.21^{\mathrm{a}}$ & $30.48 \pm 0.13^{\mathrm{b}}$ \\
PUFA & $21.69 \pm 0.12^{\mathrm{b}}$ & $37.68 \pm 0.18^{\mathrm{a}}$ \\
n-3/n-6 & $0.60 \pm 0.03^{\mathrm{b}}$ & $4.73 \pm 0.16^{\mathrm{a}}$ \\
Al & $0.68 \pm 0.05^{\mathrm{a}}$ & $0.42 \pm 0.04^{\mathrm{b}}$ \\
\hline
\end{tabular}

a,b Values in the same line with different lowercase letters are significantly differen at $P<0.05$. nd, not detected. Abbreviations: SFA, saturated fatty acid; MUFA, monounsaturated fatty acid; PUFA, polyunsaturated fatty acid; $\mathrm{Al}$, atherogenicity index; $\mathrm{TI}$, thrombogenicity index.

didyma, they turn out to be potential diet for the diverse nutritional and healthy functions.

\subsection{Fatty acid composition}

The FA composition showed significantly difference between the two species. As shown in Table 3, the lipid from Chlorostoma rusticum included large level of monounsaturated fatty acids (MUFA) ( $43.10 \%$ of total FA), medium level of saturated fatty acids (SFA) (35.21\% of total FA) and low level of PUFA (21.69\% of total FA). Among PUFA, DHA and EPA only accounted for 0.40 and $3.17 \%$ of total FA, respectively. However, Neverita didyma had a proportion of PUFA (37.68\% of total FA), MUFA (32.06\% of total FA) and SFA ( $30.48 \%$ of total FA), which was close to the ratio of $1: 1: 1$ that recommend by WHO. In addition, n-3 PUFA like DHA and
EPA both accounted for over $11 \%$ of total FA.

Previous studies also have shown that FA profiles varied significantly among different species of whelks. For example, PUFA accounted for $44.8 \%$ of total FA in whelk Rapana Thomasiana, furthermore, DHA and EPA accounted for 5.68 and $7.77 \%$ of total FA, respectively (Christie et al., 1988). However, according to Saito and Aono (2014), lipid from sea snail Turbo cornutus contained a relative low percentage of PUFA $(28.60 \%)$. Moreover, there was no DHA but low amount of EPA (3.20\% of total FA) in Turbo cornutus lipid.

\subsection{Characterization of glycerophospholipid molecular species}

In the present study, GP molecular species were characterized with the shotgun lipidomic approach through character scan mode. After PIS scan with $\mathrm{m} / \mathrm{z} 184$ in positive ion mode for GPCho/LGPCho, NLS scan with $\mathrm{m} / \mathrm{z} 141,185$ and 260 in positive ion mode for GPEtn/LGPEtn, GPSer/LGPSer and GPIns/LGPIns, respectively, the candidate compounds of each class of the afore-mentioned GP showed visible first-stage MS signals in the PIS or NLS MS spectra (Figure 1). The measured $\mathrm{m} / \mathrm{z}$ value represent the molecular ion $\left([\mathrm{M}]^{+}\right)$for GPCho/LGPCho, and the quasi-molecular ion $\left([\mathrm{M}+\mathrm{H}]^{+}\right)$of GPEtn/LGPEtn, GPSer/LGPSer and GPIns/LGPIns, respectively. Thus, the molecular mass of the unknown GP could be determined.

Common structural for the GP molecular species follows the format $\mathrm{x}: \mathrm{y}$, in which $\mathrm{x}$ and $\mathrm{y}$ representing the number of carbons and double bonds of FA esterified in GP, respectively (Peterson and Cummings, 2006). For the lysoglycerophospholipid (LGP) molecular species, the structure could be distinguished directly according to the measured $\mathrm{m} / \mathrm{z}$ by the formula established in our previous (Liu et al., 2017; Yin et al., 2016). Follow this procedure, the molecular species of all detected LGP in whelk lipids were characterized (Table s1).

For an unknown GP, which contain two FAs esterified to the $s n-1$ and $s n-2$ positions of the glycerol backbone, MS and MS/ MS data are both essential for molecular structure elucidation. The total number of carbons and double bonds of the two FAs can be tentatively deduced according to the formulas we previously developed based on their measured molecular mass (Liu et al., 2017; Yin et al., 2016). After EPI scan in the negative ion mode, at least one FAs of the unknown GP can be ascertained by the FA anions $\left([\mathrm{RCOO}]^{-}\right)$in $\mathrm{MS} / \mathrm{MS}$ data acquired (Table s2). With the known information of the total number of carbons and double bonds of the two FAs, and one of the FA, the other FA of GP can be easily deduced. Moreover, other fragments such as lyso-GP anions due to the loss of FA were also observed in MS/MS data (Table s2), which further confirmed the reliability of characterization of molecular species. Furthermore, an empirical rule that the $s n-2$ of GP is the preferred position for the more unsaturated fatty acids was used to determine the distribution of the two FAs in the glycerol backbone (Napolitano et al., 1992). Through the above strategy, all detected phosphatidyl GPCho, GPEtn, GPSer and GPIns were characterized with unsaturated FA at $s n-2$ position. (Table s2).

The strategy for structural characterization of plasmalogen (plasmenyl and plasmanyl) GP was similar with that of phosphatidyl GP. However, it was hard to distinguish a plasmanyl GP x:y from a plasmenyl GP $\mathrm{x}:(\mathrm{y}-1)$ for their same first-stage MS and MS/MS data due to the specific fatty acid fragment (ether-like anions, $\left[\mathrm{RCO}^{-}\right)$of alkyl ether $\mathrm{x}: \mathrm{y}$ and vinyl ether $\mathrm{x}:(\mathrm{y}-1)$ that released from the $s n-1$ position of the plasmanyl and plasmenyl GP. Therefore, in the present work, a pair of possible structures including a plasmanyl GP $\mathrm{x}$ :y and a plasmenyl GP $\mathrm{x}:(\mathrm{y}-1)$ corresponding 

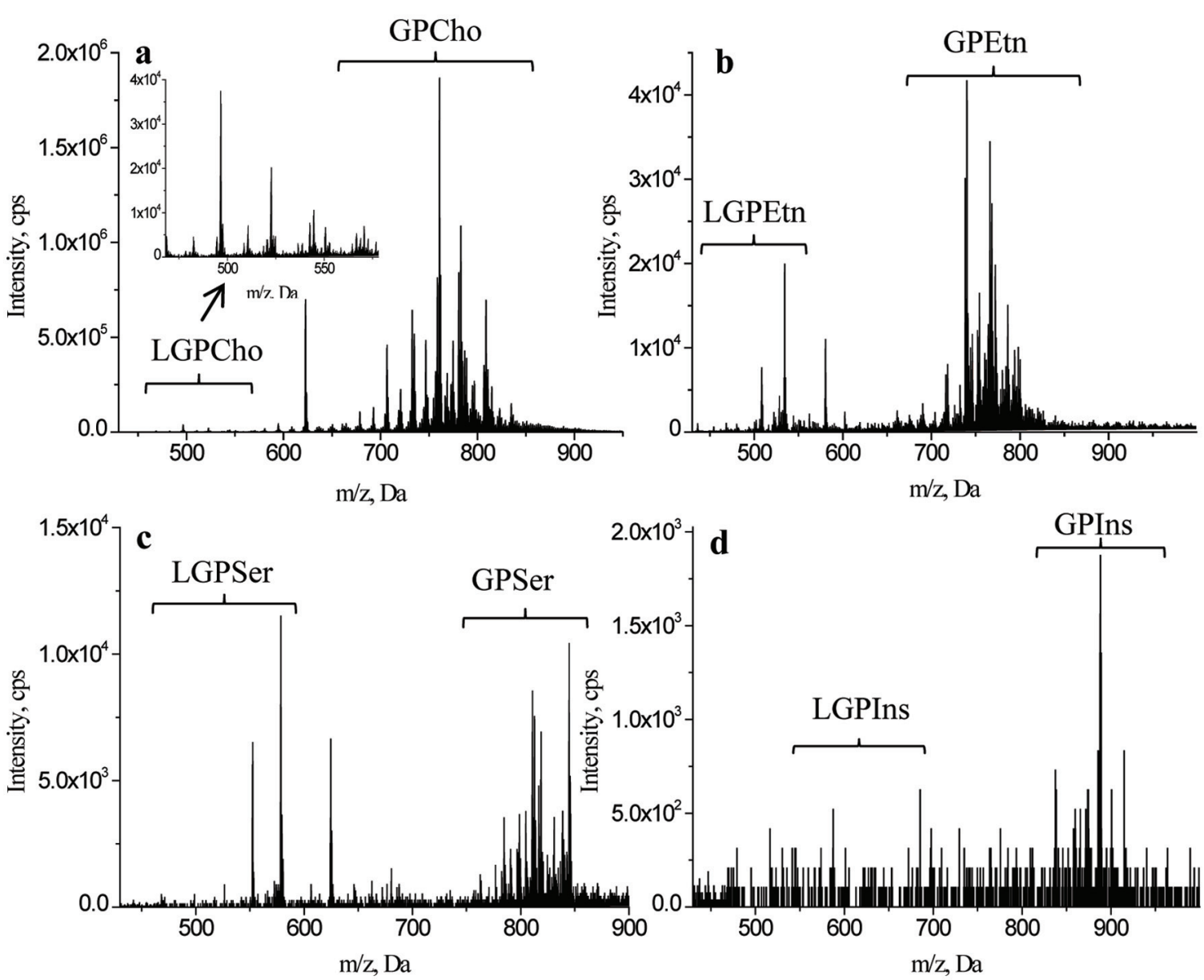

Figure 1. Specific detection of glycerophospholipids in lipids recovered from two species of whelks by using direct infusion mass spectrometric approaches. a-d, first-stage MS spectra of glycerophosphocholines (GPCho)/lysoglycerophosphocholines (LGPCho), glycerophosphoethanolamines (GPEtn)/lysoglycerophosphoethanolamines (LGPEtn), glycerophosphoserines (GPSer)/lysoglycerophosphoserines (LGPSer), and glycerophosphatidylinositol (GPIns)/ lysoglycerophosphatidylinositol (LGPIns), respectively.

to the same first-stage MS and MS/MS data were counted as one GP because they could not be differentiated (Table s2).

\subsection{Glycerophospholipid molecular species in different whelk species}

As shown in Tables 4, s3 and s4, more than 210 species of GP including GPCho, LGPCho, GPEtn, LGPEtn, GPSer, LGPSer, GPIns and LGPIns were characterized in lipids extracted from the two species of whelks. Or rather, at least 43 and 54 species of GPCho, 41 and 46 species of GPEtn, 27 and 36 species of GPSer, as well as 13 and 12 species of GPIns were characterized. Among them, 18:0/22:6, 16:0/18:1, 16:0/20:5 and 18:1/20:4 were the predominant species of the phosphatidyl subclass, 16:0/20:4 and 20:0/20:1 might be the predominant species of the plasmenyl subclass, 18:0/20:5, 16:0/22:6 and 20:0/20:1 might be the predominant species of the plasmanyl subclass (Table s4). In addition, for the lyso-GP, at least 14 and 21 species of LGPCho, 27 and 24 species of LGPEtn, 25 and 25 species of LGPSer, and 22 and 18 species of LGPIns were characterized from Chlorostoma rusticum and Neverita didyma, respectively (Tables 4, s1-s4). Among them, 18:1, 20:1, 20:5, 22:5 and 22:6 were the predominant species of the lyso-GP (Table 4).
The analysis of FA compositions in PL has also proved that some classes of PL from whelk are abundant in PUFA. For example, Saito and Hashimoto (2010) reported that PC from black snail (Ifremeria nautilei) contained a large proportion of PUFA, especially EPA $(8.70 \%)$, while Stuart et al (1998) reported that PE in snail Cepaea nemoralis was also rich in n-3 PUFA, particularly EPA (6.34\%) and docosapentenoic acid (DPA) (8.24\%). Meanwhile, some scholars devoted on PL molecular species in lipids from marine bivalves have also observed that the predominant species of GP contained PUFA. For example, the predominant GP species in lipids from mussel, clams and oysters normally contained 20:5 and 22:6 (Boselli et al., 2012; Chen et al., 2012; Liu et al., 2017; Yin et al., 2016). In this study, Chlorostoma rusticum and Neverita didymas had a large amount of PL molecular species that contained 20:5 and 22:6 in the structure. As described above, FA composition analysis indicated that there were no other 20:5 and 22:6 than EPA and DHA present in lipids form the whelk lipids. Therefore, the two whelks serve as potential source for PL enriched EPA and DHA.

It is well accepted that n-3 LC-PUFA, especially EPA, DPA and DHA, play significant roles in various aspects of human health, especially in reducing the risk of cardiovascular disease, hypertension, inflammation, allergies, immune, renal disorders and enhancing brain function (Riediger et al., 2009). Therefore, daily 
Table 4. Major molecular species of glycerophosphocholines, glycerophosphoethanolamines, glycerophosphatidylserines, glycerophosphatidylinositols and their lyso- counterparts in lipids recovered from two species of whelks. The ratio of the intensity of the first-stage MS signal of a glycerophospholipid in the positive ion mode to that of the corresponding internal standard was used to represent its relative amount for comparison

\begin{tabular}{|c|c|c|c|c|}
\hline \multirow{2}{*}{ Classes } & \multirow{2}{*}{ Measured $\mathrm{m} / \mathrm{z}\left([\mathrm{M}]^{+}\right)$or $\left([\mathrm{M}+\mathrm{H}]^{+}\right)$} & \multirow{2}{*}{ Molecular species } & \multicolumn{2}{|c|}{ Relative intensity } \\
\hline & & & Chlorostoma rusticum & Neverita didyma \\
\hline \multirow[t]{6}{*}{ GPCho } & 760 & $\begin{array}{l}\text { Phosphatidyl 17:0/17:1 } \\
\text { Phosphatidyl 16:0/18:1 }\end{array}$ & $2.75 \pm 0.07^{a}$ & $1.29 \pm 0.08^{b}$ \\
\hline & 766 & $\begin{array}{l}\text { Plasmanyl 16:1/20:4 } \\
\text { Plasmenyl 16:0/20:4 } \\
\text { Plasmanyl 16:0/20:5 }\end{array}$ & $0.28 \pm 0.01^{b}$ & $2.97 \pm 0.01^{\mathrm{a}}$ \\
\hline & 780 & Phosphatidyl 16:0/20:5 & $1.28 \pm 0.07^{\mathrm{b}}$ & $2.73 \pm 0.02^{\mathrm{a}}$ \\
\hline & 782 & Phosphatidyl 16:0/20:4 & $1.69 \pm 0.02^{\mathrm{a}}$ & $1.29 \pm 0.08^{b}$ \\
\hline & 792 & Plasmanyl 16:0/22:6 & $0.19 \pm 0.01^{b}$ & $2.9 \pm 0.02^{\mathrm{a}}$ \\
\hline & 808 & $\begin{array}{l}\text { Phosphatidyl 18:1/20:4 } \\
\text { Phosphatidyl 16:0/22:5 }\end{array}$ & $1.15 \pm 0.13^{b}$ & $2.16 \pm 0.09^{a}$ \\
\hline \multirow[t]{7}{*}{ GPEtn } & 738 & Phosphatidyl 16:0/20:5 & $2.48 \pm 0.08^{a}$ & $1.57 \pm 0.01^{b}$ \\
\hline & 752 & $\begin{array}{l}\text { Plasmanyl 18:0/20:5 } \\
\text { Plasmanyl 16:0/22:5 }\end{array}$ & $1.03 \pm 0.08^{b}$ & $1.24 \pm 0.04^{a}$ \\
\hline & 766 & $\begin{array}{l}\text { Phosphatidyl 16:0/22:5 } \\
\text { Phosphatidyl 18:1/20:4 } \\
\text { Phosphatidyl 18:0/20:5 } \\
\text { Phosphatidyl 16:1/22:4 }\end{array}$ & $3.1 \pm 0.03^{b}$ & $4.11 \pm 0.04^{\mathrm{a}}$ \\
\hline & 768 & Phosphatidyl 18:0/20:4 & $2.35 \pm 0.09^{b}$ & $2.59 \pm 0.03^{a}$ \\
\hline & 772 & $\begin{array}{l}\text { Phosphatidyl 16:0/22:2 } \\
\text { Phosphatidyl 18:1/20:1 } \\
\text { Phosphatidyl 18:0/20:2 }\end{array}$ & $1.79 \pm 0.06^{b}$ & $2.32 \pm 0.02^{\mathrm{a}}$ \\
\hline & 786 & $\begin{array}{l}\text { Phosphatidyl 20:4/20:5 } \\
\text { Plasmanyl 20:1/20:1 } \\
\text { Plasmenyl 20:0/20:1 }\end{array}$ & $1.32 \pm 0.04^{b}$ & $3.01 \pm 0.04^{\mathrm{a}}$ \\
\hline & 792 & $\begin{array}{l}\text { Phosphatidyl 20:1/20:5 } \\
\text { Phosphatidyl 18:0/22:6 }\end{array}$ & $0.62 \pm 0.02^{\mathrm{b}}$ & $2.03 \pm 0.07^{a}$ \\
\hline \multirow[t]{4}{*}{ GPSer } & 810 & $\begin{array}{l}\text { Phosphatidyl 18:0/20:5 } \\
\text { Phosphatidyl 18:1/20:4 }\end{array}$ & $1.01 \pm 0.08^{b}$ & $3.86 \pm 0.02^{\mathrm{a}}$ \\
\hline & 812 & Phosphatidyl 16:0/22:4 & $1.10 \pm 0.06^{\mathrm{b}}$ & $2.41 \pm 0.06^{\mathrm{a}}$ \\
\hline & 818 & $\begin{array}{l}\text { Phosphatidyl 18:0/20:1 } \\
\text { Plasmanyl 18:2/22:6 } \\
\text { Plasmenyl 18:1/22:6 }\end{array}$ & $0.89 \pm 0.06^{b}$ & $1.43 \pm 0.04^{\mathrm{a}}$ \\
\hline & 844 & $\begin{array}{l}\text { Phosphatidyl 18:0/22:2 } \\
\text { Phosphatidyl 20:1/20:1 } \\
\text { Plasmanyl 22:4/20:5 } \\
\text { Plasmenyl 22:3/20:5 }\end{array}$ & $1.53 \pm 0.07^{\mathrm{b}}$ & $3.23 \pm 0.09^{a}$ \\
\hline \multirow[t]{2}{*}{ GPIns } & 885 & $\begin{array}{l}\text { Phosphatidyl 18:0/20:5 } \\
\text { Phosphatidyl 18:1/20:4 }\end{array}$ & $1.22 \pm 0.09^{b}$ & $5.83 \pm 0.02^{\mathrm{a}}$ \\
\hline & 887 & Phosphatidyl 18:0/20:4 & $3.57 \pm 0.06^{b}$ & $4.50 \pm 0.07^{a}$ \\
\hline \multirow[t]{4}{*}{ LGPCho } & 496.6 & Phosphatidyl 16:0 & $0.05 \pm 0.00^{\mathrm{b}}$ & $0.14 \pm 0.01^{\mathrm{a}}$ \\
\hline & 522.6 & Phosphatidyl 18:1 & $0.03 \pm 0.00^{b}$ & $0.12 \pm 0.01^{a}$ \\
\hline & 542.6 & Phosphatidyl 20:5 & $0.01 \pm 0.00^{b}$ & $0.20 \pm 0.01^{a}$ \\
\hline & 568.6 & Phosphatidyl 22:6 & $0.01 \pm 0.00^{\mathrm{b}}$ & $0.28 \pm 0.00^{a}$ \\
\hline \multirow[t]{3}{*}{ LGPEtn } & 500.3 & Phosphatidyl 20:5 & $0.08 \pm 0.03^{b}$ & $0.12 \pm 0.02^{\mathrm{a}}$ \\
\hline & 506.3 & Phosphatidyl 20:2 & $0.11 \pm 0.03$ & $0.15 \pm 0.01$ \\
\hline & 508.4 & Phosphatidyl 20:1 & $0.71 \pm 0.02^{\mathrm{a}}$ & $0.40 \pm 0.11^{b}$ \\
\hline
\end{tabular}


Table 4. Major molecular species of glycerophosphocholines, glycerophosphoethanolamines, glycerophosphatidylserines, glycerophosphatidylinositols and their lyso- counterparts in lipids recovered from two species of whelks. The ratio of the intensity of the first-stage MS signal of a glycerophospholipid in the positive ion mode to that of the corresponding internal standard was used to represent its relative amount for comparison - (continued)

\begin{tabular}{|c|c|c|c|c|}
\hline \multirow{2}{*}{ Classes } & \multirow{2}{*}{ Measured $\mathrm{m} / \mathrm{z}\left([\mathrm{M}]^{+}\right)$or $\left([\mathrm{M}+\mathrm{H}]^{+}\right)$} & \multirow{2}{*}{ Molecular species } & \multicolumn{2}{|c|}{ Relative intensity } \\
\hline & & & Chlorostoma rusticum & Neverita didyma \\
\hline & 528.4 & Phosphatidyl 22:5 & $0.34 \pm 0.07^{a}$ & $0.22 \pm 0.05^{b}$ \\
\hline & 534.4 & Phosphatidyl 22:2 & $1.65 \pm 0.25^{a}$ & $0.71 \pm 0.00^{b}$ \\
\hline \multirow[t]{4}{*}{ LGPSer } & 526.4 & Phosphatidyl 18:0 & $0.12 \pm 0.02^{\mathrm{b}}$ & $0.45 \pm 0.01^{\mathrm{a}}$ \\
\hline & 552.4 & Phosphatidyl 20:1 & $0.96 \pm 0.03^{a}$ & $0.35 \pm 0.04^{b}$ \\
\hline & 572.3 & Phosphatidyl 22:5 & $0.15 \pm 0.01^{\mathrm{a}}$ & $0.09 \pm 0.01^{b}$ \\
\hline & 578.4 & Phosphatidyl 22:2 & $1.73 \pm 0.02^{\mathrm{a}}$ & $0.52 \pm 0.06^{b}$ \\
\hline \multirow[t]{4}{*}{ LGPIns } & 579.2 & Phosphatidyl 18:4 & $0.27 \pm 0.09^{b}$ & $1.02 \pm 0.11^{\mathrm{a}}$ \\
\hline & 599.1 & Phosphatidyl 18:1 & $0.43 \pm 0.33^{b}$ & $0.50 \pm 0.18^{a}$ \\
\hline & 601.6 & Phosphatidyl 18:0 & $0.63 \pm 0.05^{a}$ & $0.50 \pm 0.18^{b}$ \\
\hline & 619.4 & Phosphatidyl 20:5 & $0.27 \pm 0.09^{b}$ & $1.02 \pm 0.11^{\mathrm{a}}$ \\
\hline
\end{tabular}

a,bValues in the same line with different lower-case letters are significantly different at $P<0.05$. The number labeled following the quantitative values indicated that the corresponding molecular species which lists in the second column of the table were present. $[\mathrm{M}]^{+}$for glycerophosphocholines and lysoglycerophosphocholines; $[\mathrm{M}+\mathrm{H}]^{+}$for glycerophosphoethanolamines, lysoglycerophosphoethanolamines, glycerophosphatidylserines, lysoglycerophosphatidylserines, glycerophosphatidylinositols and lysoglycerophosphatidylinositols. Abbreviations: GPCho, glycerophosphocholine; GPEtn, glycerophosphoethanolamine; GPSer, glycerophosphatidylserine; GPIns, glycerophosphatidylinositol; LGPCho, lysoglycerophosphocholine; LGPEtn, lysoglycerophosphoethanolamine; LGPSer, lysoglycerophosphatidylserine; LGPIns, lysoglycerophosphatidylinositols.

consumption of 250-1,000 mg of EPA/DHA for health benefit is widely recommended (Kuratko et al., 2013). The dietary sources of n-3 LC-PUFA are mainly existed in TAG and PL form, however, n-3 LC-PUFA in the PL form has captured extensive attention by consumers and scholars due to their higher bioavailability (Cook et al., 2016; Nicolson, 2014; Yurko-Mauro et al., 2015), tissue-delivery capacity (Antebi et al., 2004; Cansell, 2010; Liu et al., 2014) as well as health promoting effects (Ramprasath et al., 2013; Sampalis et al., 2003; Ulven et al., 2011) compared with n-3 LC-PUFA in TAG form. Therefore, the nutritional and healthy functions of whelk may partly be ascribed to the n-3 LC-PUFA enriched in PL.

\section{Conclusion}

Dried whelks (Chlorostoma rusticum and Neverita didyma) tissues contained 13.67 and $7.12 \%$ of lipids, respectively. The lipids mainly consist of PL, TAG, DAG, MAG, FFA and CHO, among which PL (52.70-58.86\% of total lipids) and TAG (31.91-32.01\% of total lipids) were dominant. For PL, PC (50.58-52.41 mol\%) was the major components. Compared with Chlorostoma rusticum, Neverita didyma had higher level of PUFA $(37.68 \%$ of total FA), especially EPA ( $11.00 \%$ of total FA) and DHA (11.10\% of total FA). At least 212 and 236 GP molecular species were characterized, respectively, in whelks Chlorostoma rusticum and Neverita didyma. Based on the amount of the molecular species containing EPA and DHA, Neverita didyma was the better fit species for GP. Obviously, whelks Chlorostoma rusticum and Neverita didyma are rich source of n-3 LC-PUFA existed in PL form. Therefore, the lipid quality of marine whelks may account for much of their nutritional and bioactive functions.

\section{Acknowledgments}

This work was financially supported by "The National Natural
Science Foundation of China (31871759; U1808203)", "National Key R\&D Program of China (2018YFD0901002)", and "Project of Distinguished Professor of Liaoning Province (2015-153)".

\section{Supporting information}

Table s1. Lysoglycerophosphocholines in lipids recovered from two species of whelks. The ratio of the intensity of the first-stage MS signal of a lysoglycerophosphocholine in the positive ion mode to that of the corresponding internal standard was used to represent its relative amount for comparison.

Table s2. Structural identification of glycerophosphocholines in whelk lipids according to first-stage MS and MS/MS data.

Table s3. Glycerophosphocholines in lipids recovered from two species of whelks. The ratio of the intensity of the first-stage MS signal of a glycerophosphocholine in the positive ion mode to that of the corresponding internal standard was used to represent its relative amount for comparison.

Table s4. The number of molecular species of glycerophosphocholines, glycerophosphoethanolamines, glycerophosphatidylserines, glycerophosphatidylinositols, lysoglycerophosphocholines, lysoglycerophosphoethanolamines, lysoglycerophosphatidylserines and lysoinglycerophosphatidylinositols in lipids recovered from two species of whelks.

\section{References}

Ali, A.H., Zou, X., Abed, S.M., Korma, S.A., Jin, Q.Z., and Wang, X.G. (2019) Natural phospholipids: Occurrence, biosynthesis, separation, identification, and beneficial health aspects. Crit. Rev. Food Sci. 59(2): 253-275.

Antebi, H., Mansoor, O., Ferrier, C., Tétégan, M., Morvan, C., Rangaraj, J., and Alcindor, L.G. (2004). Liver function and plasma antioxidant 
status in intensive care unit patients requiring total parenteral nutrition: comparison of 2 fat emulsions. J. Parenteral Enteral Nutri. 28: 142-148.

Arranz, E., and Corredig, M. (2017). Invited review: Milk phospholipid vesicles, their colloidal properties, and potential as delivery vehicles for bioactive molecules. J. Dairy Sci 100: 4213-4222.

Asomaning, J., Zhao, Y.Y., Lewis, E.D., Wu, J., Jacobs, R.L., Field, C.J., and Curtis, J.M. (2017). The development of a choline rich cereal based functional food: Effect of processing and storage. LWT-Food Sci. Technol 75: 447-452.

Barden, L., and Decker, E.A. (2016). Lipid oxidation in low-moisture food: a review. Crit. Rev. Food Sci. 56: 2467-2482.

Beach, D.G., Quilliam, M.A., and Hellou, J. (2009). Analysis of pyrene metabolites in marine snails by liquid chromatography using fluorescence and mass spectrometry detection. J. Chromatogr B 87: 2142-2152.

Boselli, E., Pacetti, D., Lucci, P., and Frega, N.G. (2012). Characterization of phospholipid molecular species in the edible parts of bony fish and shellfish. J. Agric. Food Chem 60: 3234-3245.

Calzada, E., Onguka, O., and Claypool, S.M. (2016). Phosphatidylethanolamine metabolism in health and disease. Int. Rev. Cell. Mol. Biol 321: $29-88$.

Cansell, M. (2010). Marine phospholipids as dietary carriers of long-chain polyunsaturated fatty acids. Lipid Technol. 22: 223-226.

Carrasco, S.A., Phillips, N.E., and Sewell, M.A. (2016). Maternal lipid provisioning mirrors evolution of reproductive strategies in direct-developing whelks. The Biol. Bull. 230: 188-196.

Chen, S., Belikova, N.A., and Subbaiah, P.V. (2012). Structural elucidation of molecular species of pacific oyster ether amino phospholipids by normal-phase liquid chromatography/negative-ion electrospray ionization and quadrupole/multiple-stage linear ion-trap mass spectrometry. Anal. Chim. Acta 735: 76-89.

Christie, W.W., Brechany, E.Y., and Stefanov, K. (1988). Silver ion highperformance liquid chromatography and gas chromatography-mass spectrometry in the analysis of complex fatty acid mixtures: application to marine invertebrates. Chem. Phys. Lipids 46: 127-135.

Cilla, A., Diego Quintaes, K., Barberá, R., and Alegría, A. (2016). Phospholipids in human milk and infant formulas: benefits and needs for correct infant nutrition. Crit. Rev. Food Sci. 56: 1880-1892.

Cook, C.M., Hallaråker, H., Sæbø, P.C., Innis, S.M., Kelley, K.M., Sanoshy, K.D., and Maki, K.C. (2016). Bioavailability of long chain omega-3 polyunsaturated fatty acids from phospholipid-rich herring roe oil in men and women with mildly elevated triacylglycerols. Prostaglandins Leukot. Essent. Fatty Acids 111: 17-24.

Gang, K.Q., Zhou, D.Y., Lu, T., Liu, Z.Y., Zhao, Q., Xie, H.K., Song, L., and Shahidi, F. (2018). Direct infusion mass spectrometric identification of molecular species of glycerophospholipid in three species of edible whelk from Yellow Sea. Food Chem. 245: 53-60.

Glade, M.J., and Smith, K. (2015). Phosphatidylserine and the human brain. Nutrition 31: 781-786.

Kooijman, E.E., and Burger, K.N. (2009). Biophysics and function of phosphatidic acid: a molecular perspective. Biochim. Biophys. Acta-Mol. Cell Biol Lipids. 1791: 881-888.

Küllenberg, D., Taylor, L.A., Schneider, M., and Massing, U. (2012). Health effects of dietary phospholipids. Lipids in Health and Dis. 11: 3.

Kuratko, C., and Salem, N. Jr (2013). Standards for preventing and treating omega-3 fatty acid deficiency. The omega-3 fatty acid deficiency syndrome, The omega-3 fatty acid deficiency syndrome: opportunity for disease prevention. In: McNamara, R. (Ed.). Nova Science Publishers, New York, pp. 399-420.

Liu, L., Bartke, N., Van Daele, H., Lawrence, P., Qin, X., Park, H.G., and Brenna, J.T. (2014). Higher efficacy of dietary DHA provided as a phospholipid than as a triglyceride for brain DHA accretion in neonatal piglets. J. Lipid Res. 55: 531-539.

Liu, Z.Y., Zhou, D.Y., Zhao, Q., Yin, F.W., Hu, X.P., Song, L., Qin, L., Zhang, J.R., Zhu, B.W., and Shahidi, F. (2017). Characterization of glycerophospholipid molecular species in six species of edible clams by high- performance liquid chromatography-electrospray ionization-tandem mass spectrometry. Food Chem. 219: 419-427.

Matyash, V., Liebisch, G., Kurzchalia, T.V., Shevchenko, A., and Schwudke, D. (2008). Lipid extraction by methyl-tert-butyl ether for highthroughput lipidomic. J. Lipid Res. 49: 1137-1146.

Miletic, I., Miric, M., Lalic, Z., and Sobajic, S. (1991). Composition of lipids and proteins of several species of molluscs, marine and terrestrial, from the Adriatic Sea and Serbia. Food Chem. 41: 303-308.

Napolitano, G.E., MacDonald, B.A., Thompson, R.J., and Ackman, R.G. (1992). Lipid composition of eggs and adductor muscle in giant scallops (Placopecten magellanicus) from different habitats. Mar. Biol. 113: 71-76.

Nicolson, G.L. (2014). The Fluid-Mosaic model of membrane structure: still relevant to understanding the structure, function and dynamics of biological membranes after more than 40 years. Biochim. Biophys. Acta (BBA)-Biomembr 1838: 1451-1466.

Peterson, B.L., and Cummings, B.S. (2006). A review of chromatographic methods for the assessment of phospholipids in biological samples. Biomed. Chromatogr. 20: 227-243.

Ramprasath, V.R., Eyal, I., Zchut, S., and Jones, P.J. (2013). Enhanced increase of omega-3 index in healthy individuals with response to 4-week n-3 fatty acid supplementation from krill oil versus fish oil. Lipids in Health and Dis. 12: 178.

Restuccia, D., Spizzirri, U.G., Puoci, F., Cirillo, G., Vinci, G., and Picci, N. (2012). Determination of phospholipids in food samples. Food Rev. Int. 28: 1-46.

Riediger, N.D., Othman, R.A., Suh, M., and Moghadasian, M.H. (2009). A systemic review of the roles of $n-3$ fatty acids in health and disease. J. Am. Diet, Assoc. 109: 668-679.

Saito, H., and Aono, H. (2014). Characteristics of lipid and fatty acid of marine gastropod Turbo cornutus: High levels of arachidonic and n-3 docosapentaenoic acid. Food Chem. 145: 135-144.

Saito, H., and Hashimoto, J. (2010). Characteristics of the fatty acid composition of a deep-sea vent gastropod, Ifremeria nautilei. Lipids 45: 537-548.

Sampalis, F., Bunea, R., Pelland, M.F., Kowalski, O., Duguet, N., and Dupuis, S. (2003). Evaluation of the effects of Neptune krill oil on the management of premenstrual syndrome and dysmenorrheal. Altern. Med. Rev 8: 171-179.

Stuart, J.A., Gillis, T.E., and Ballantyne, J.S. (1998). Remodeling of phospholipid fatty acids in mitochondrial membranes of estivating snails. Lipids 33: 787-793.

Tang, B., Wei, W., Huang, Y., Zou, X., and Yue, Y. (2016). Growth performance and nutritional composition of Hemifusus ternatanus under artificial culturing conditions. Aquaculture 459: 186-190.

Ulven, S.M., Kirkhus, B., Lamglait, A., Basu, S., Elind, E., Haider, T., Berge, K., Vik, H., and Pedersen, J.I. (2011). Metabolic effects of krill oil are essentially similar to those of fish oil but at lower dose of EPA and DHA, in healthy volunteers. Lipids 46: 37-46.

Yin, F.W., Liu, X.Y., Fan, X.R., Zhou, D.Y., Xu, W.S., Zhu, B.W., and Murata, Y. (2015). Extrusion of Antarctic krill (Euphausia superba) meal and its effect on oil extraction. Int. J. Food Sci. \& Technol. 50: 633-639.

Yin, F.W., Zhou, D.Y., Zhao, Q., Liu, Z.Y., Hu, X.P., Liu, Y.F., Song, L., Zhou, X., Zhu, B.W., and Shahidi, F. (2016). Identification of glycerophospholipid molecular species of mussel (Mytilus edulis) lipids by highperformance liquid chromatography-electrospray ionization-tandem mass spectrometry. Food Chem. 213: 344-351.

Yurko-Mauro, K., Kralovec, J., Bailey-Hall, E., Smeberg, V., Stark, J.G., and Salem, N. (2015). Similar eicosapentaenoic acid and docosahexaenoic acid plasma levels achieved with fish oil or krill oil in a randomized double-blind four-week bioavailability study. Lipids in Health and Dis. 14: 99.

Zarai, Z., Frikha, F., Balti, R., Miled, N., Gargouri, Y., and Mejdoub, H. (2011). Nutrient composition of the marine snail (Hexaplex trunculus) from the Tunisian Mediterranean coasts. J. Sci. Food Agric 91: 1265-1270.

Zhukova, N.V. (2014). Lipids and fatty acids of nudibranch mollusks: Potential sources of bioactive compounds. Mar. Drugs 12: 4578-4592. 